\title{
WINE TRADING - A FACTOR FOR THE DEVELOPMENT OF WINE VINE GROWING IN BULGARIA
}

\author{
R. Otuzbirov ${ }^{1 *}$, G. Aleksiev, A. Petkova ${ }^{2}$ \\ ${ }^{1}$ Faculty of Economics, Trakia University, Stara Zagora, Bulagria \\ ${ }^{2}$ Giesecke \& Revrient, Munich, Germany
}

\begin{abstract}
Winemaking is a traditionally successful branch of industry in Bulgaria. With a share of about $2 \%$ of the world market, Bulgaria is in the first third of the world's leading producer and exporter of wine, and has positioned itself between 21-24 spots (1) in recent years. Wine is among the ten most exported Bulgarian products, with more than 50 larger wineries and many wineries producing different bottled and sparkling wines. Data on wine volumes in recent years have shown a preference for domestic entities to export compared to selling their products in the home market, which, despite logistical costs and additional risks, is expected to be rewarded with higher profits.
\end{abstract}

Key words: wine, import, export, trends

\section{INTRODUCTION}

Winemaking is a traditionally successful branch of industry in Bulgaria. With a share of about $2 \%$ of the world market, Bulgaria is in the first third of the world's leading producer and exporter of wine, and has positioned itself between 21-24 (1) in recent years. Wine is among the ten most exported Bulgarian products, with more than 50 larger wineries and many wineries producing different bottled and sparkling wines.

Trade and its inherent indicators for Bulgarian wine are diametrically different in their development compared to those of grapes, with the differences reaching more than 10 times the last 2014. Until 2007 The levels of trade are relatively constant and lie about $91815 \mathrm{t}$. For export and 2965 t. For imports, with almost $95 \%$ of trade already in favor of exports.

\section{RESAULTS}

After 2007, there is a significant reduction in physical volumes compared to the preaccession period, falling to $63 \%$ of its previous volume as shown on Figure 1.

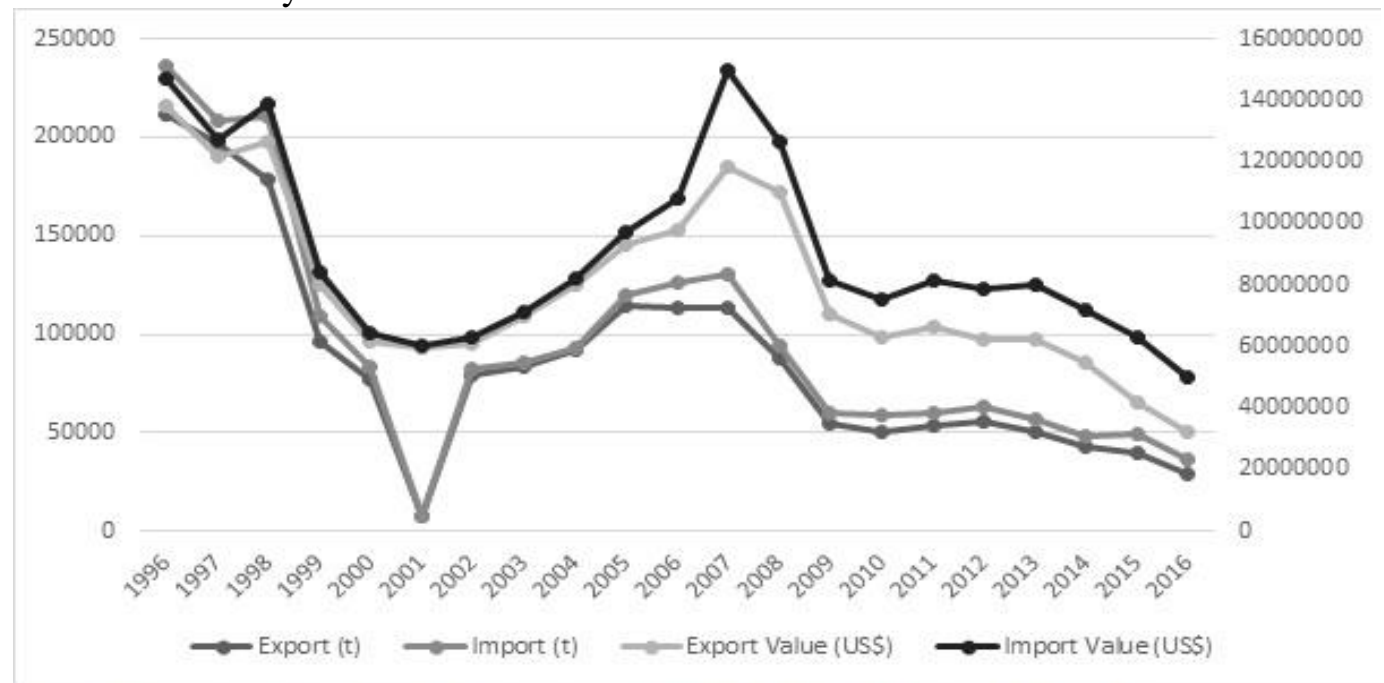

Figure 1: Dynamics of the import and export of wine: 1996 - 2016; (t) \& (price in US dollars)

\footnotetext{
*Correspondence to: Roumen Otuzbirov, Faculty

of Economics, Trakia University - Stara Zagora,

Studentski grad, 6000 Stara Zagora, Bulagria,

042/699444, E-mail:otuzbirov_r@abv.bg
} 
Exports retain their ranking but are around $91 \%$ of traded volumes, while imports are between $2 \%$ and $16.5 \%$ over the period under review (2). That is a positive fact, although in a smaller volume than the pre - accession period, Bulgaria is currently enjoying a relatively stable export rate - approximately 52,500 tons. Per annum, the equivalent in value terms also shows stability, ranging around EUR 49000.

Also positive is the fact that the difference between the value and the quantitative indicators has already presented in the export quantities. The latter is evidence of less output, but a higher price segment.

\section{OTUZBIROV R., et al.}

Imports show a more gradual development, not only in absolute values, but also as a dynamics of the process. After 2007 A relatively stable trend is observed at levels of about 7,300 tons. For a price of EUR 10700 . The fact is that, unlike in the export, the prices are higher per unit. We import more expensive wine, probably due to more demanding requirements of sophisticated and capricious customers (3).

Figure 2 shows the dynamics of average import and export prices for wine for the period under review. Presenting the average as indicator, the export price is almost twice as high, indicating a positive assessment of Bulgarian wine.

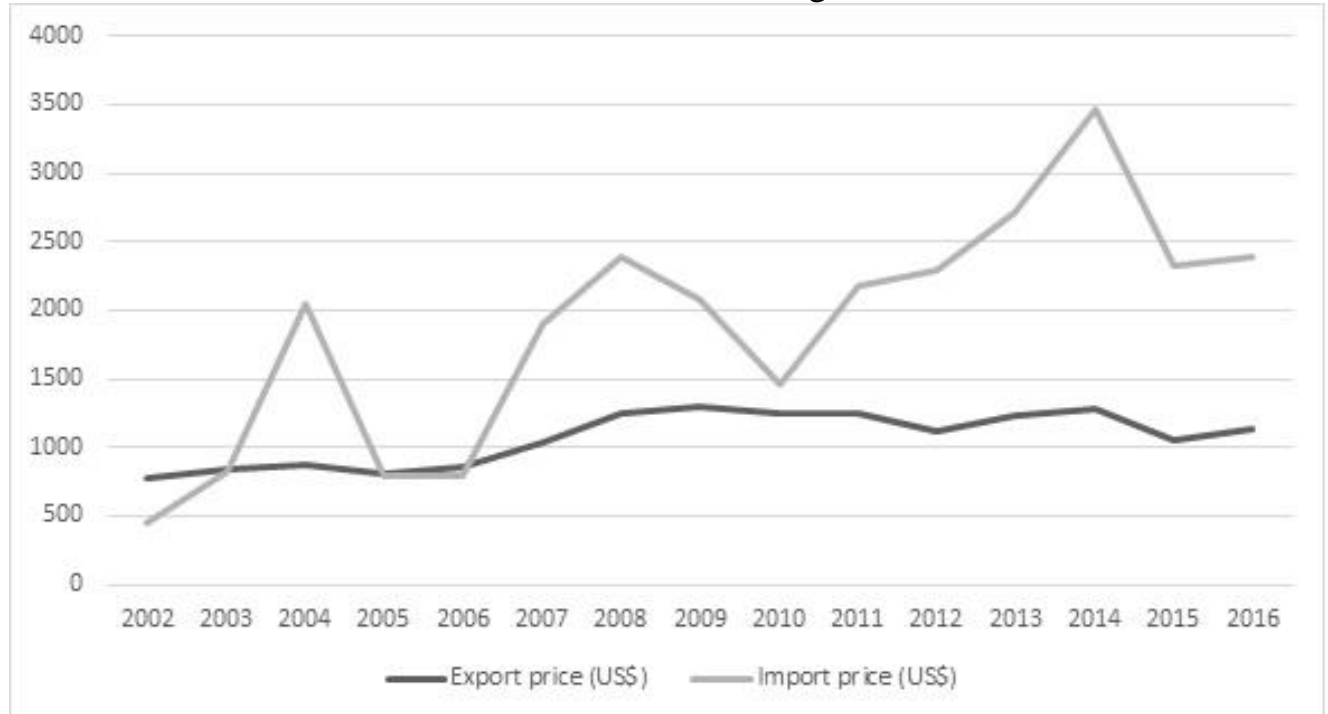

Figure2: Dynamics of the arerage export and import price of wine: 2002 - 2016

Price levels are currently set at EUR 1967.4 per ton for exports and EUR 978.8 per ton for imports.

The next pair of figures - Figure 3 and Figure 4 show the structure of imports and exports by type of wine product. For exports throughout the period under review, bottled wines are a leading product and maintain an average $88 \%$ relative share, pouring ranges around $23.4 \%$ and sparkling on average $1.1 \%$. Positive is the fact of the excess of bottled wines in our exports, as this shows that the product is marketed as itself and not as a raw material for subsequent coupling, which is a signal for its perceived quality abroad.

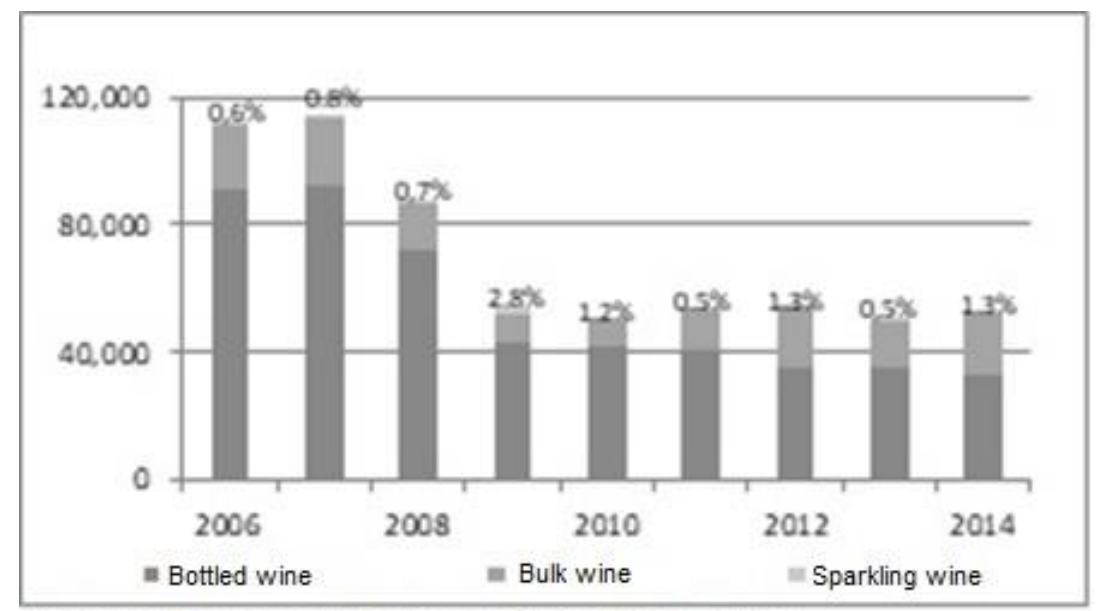

Figure 3: Structure of the export of mine: $2006-2014$ 


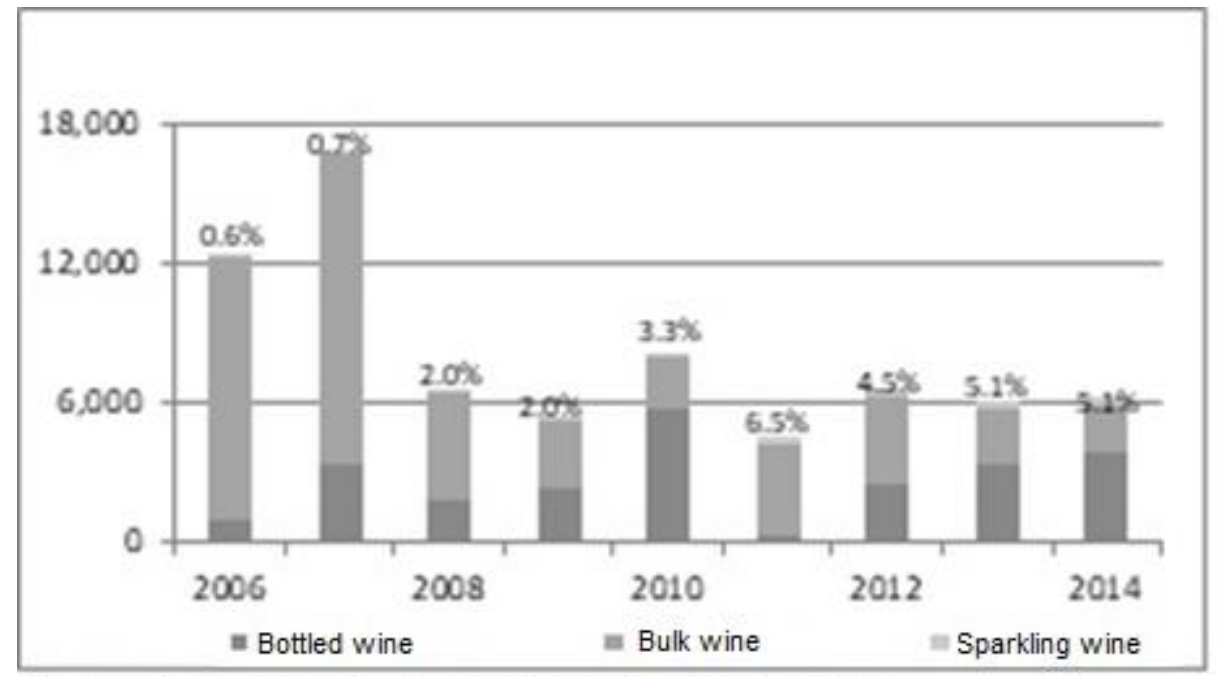

Figure 4: Structure of the import of trine: $2006-2014$

Import quantities are about 6 times lower and show different distribution. Sparkling wines traditionally record low values and range around 3.3\% over the period. Imports of draft wines are extremely dominant, past 2007 (4). Their volumes gradually declined and in the last two years they are already occupying about $37 \%$, at the expense of bottled wines that drop to $59 \%$. The latter speaks of a change in the culture of the Bulgarian consumer and is somewhat related to the policy of diversified supply of already widespread commercial chains in Bulgaria.

As for the trading partners for the product bottled wines, there are also significant changes as shown on Figure 5.

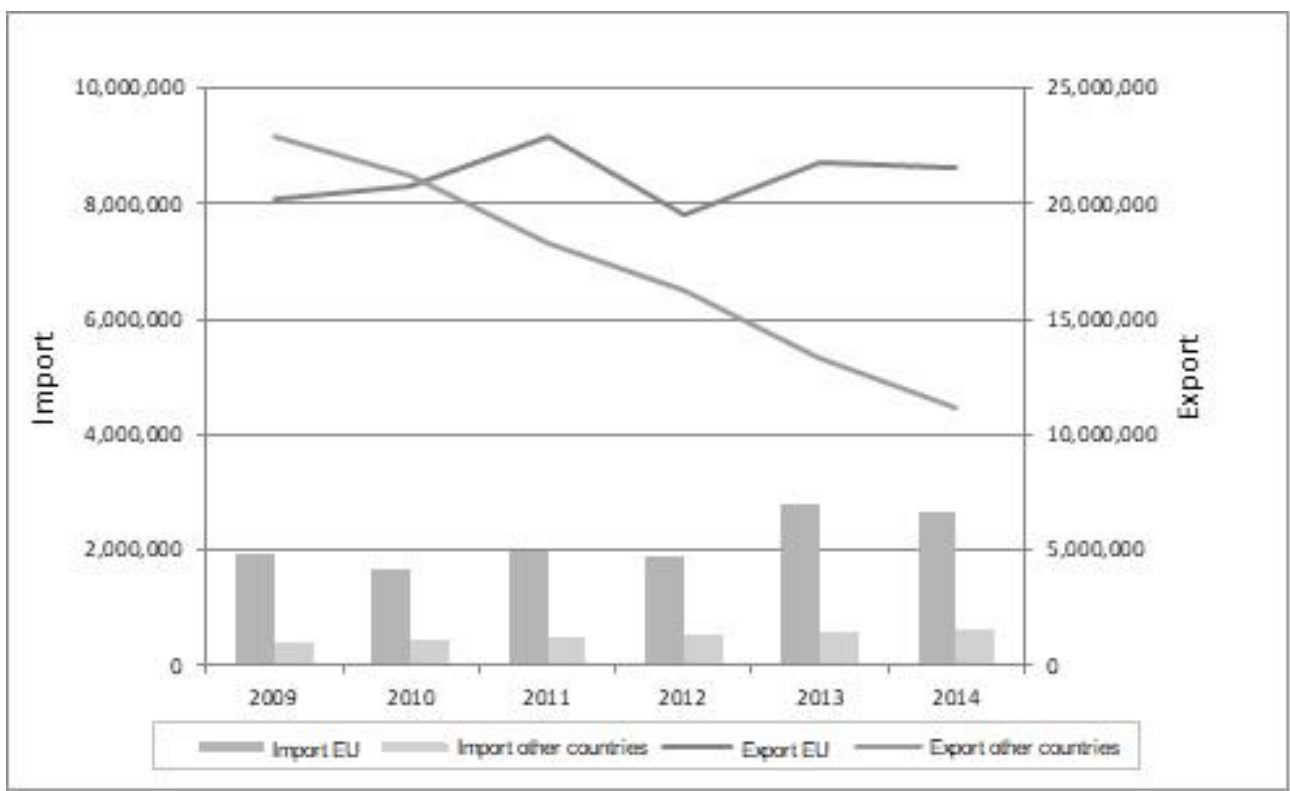

Figure 5: Dynamics of the import and export of bottled wine: 2009 - 2014

In essence, the change is a reallocation among major trading partners after 2010. In reality, partner countries are generally retained, but the volumes of traded volumes are changing (5). While in the first years mainly bottled wines are exported to third countries, after 2010, the direction turns to the EU market. Thus the volumes of traded wine on the world market declines after 2010. The traded volumes for other than EU member countries of almost 23 000 thousand liters in 2009 fall to 11,000 thousand in 2014, which is amounting to
47.8\%. Some countries, like Canada and Belarus, are showing a decline of more than 5 times. Main partners include Russia, the US, China, Mongolia and Japan in most years.

Exports to EU countries are not constant in their development, but show a steady trend, ranging around 21,130,000 liters per year. In Europe, the largest quantities of bottled wines are exported to Poland, Romania, the Czech Republic, the United Kingdom, Slovakia, 
Greece, Germany, Lithuania, Belgium and Italy.

Regarding imports of bottled wines, it can be said that the observed increase is also in the direction of the EU countries and third countries, the latter being with a higher rate of increase. However, EU import volumes remain almost four times higher, averaging around 2 160 thousand liters per year, while those from third countries averaging 500 thousand liters per year respectively. The main partners for importing wines outside of the EU are: Chile, New Zealand, Turkey, Macedonia, South Africa and Argentina. A from the Community is imported most from Slovakia, France, Italy, Spain, the United Kingdom, Greece and the Netherlands.
It can be noted that combined data on wine volumes in recent years have shown the preference of domestic entities to export compared to selling their product on the domestic market, which, despite logistical costs and additional risks, is expected to be rewarded with higher profit. Bottled wines are mainly exported, and in recent years the focus has been on the European market (6). Wine import data shows an interest in bottled wines, high quality and in the high price segment, which satisfy the sophisticated taste of a small percentage of consumers.

The high levels of grape imports imply an insufficiency of raw material on a national scale and the specialization of the economic units in the processing and production of wine instead of growing vineyards.

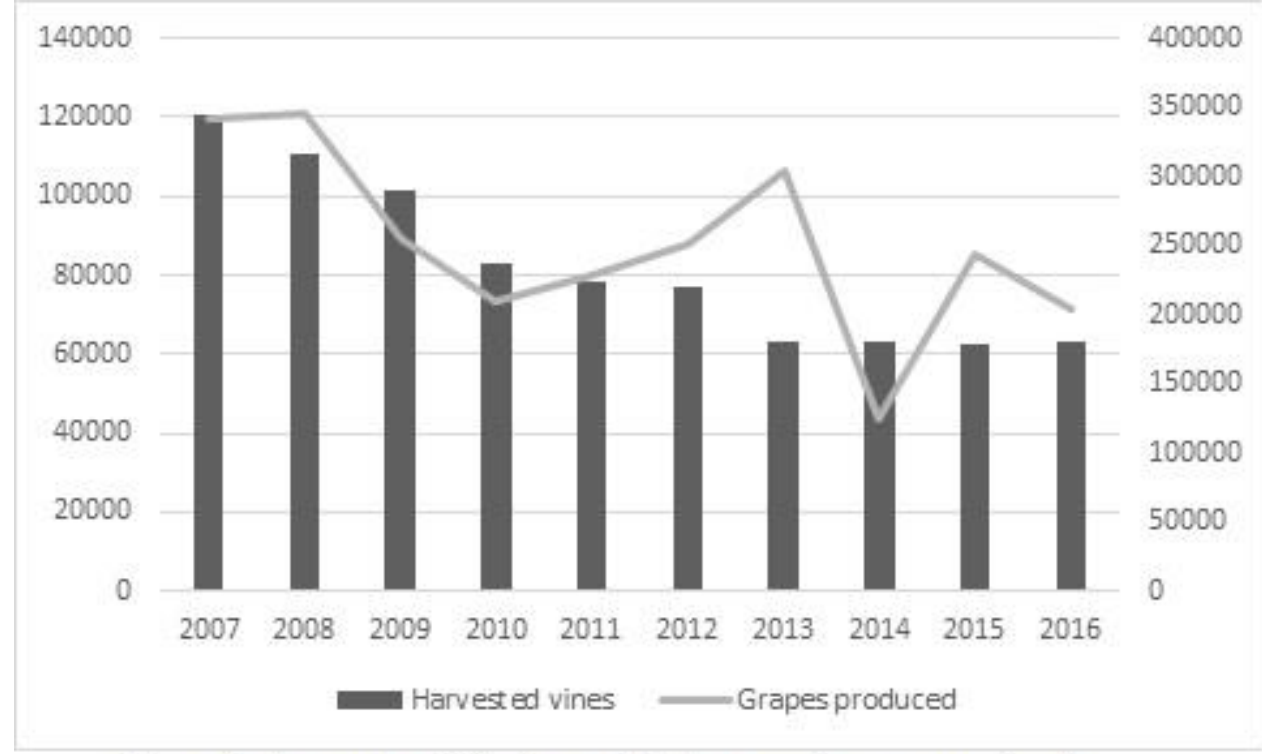

Figure 6: Dynamics of the harvested vines and grapes produced

Figure 6 shows the dynamics of the cultivated vineyards in the country after our accession to the EU. After 2012 the volume of the vineyards does not change, while the quantity of grapes produced is marked by serious fluctuations. This is due both to the dynamics of climatic conditions during various years, and to the uncertainty faced by producers in the realization of their wine production on international markets. The declining export volumes of Bulgarian wine during the period led to a reduced willingness for additional investments in the sector and cost optimization through a weaker load on the production capacity in the sector.

\section{CONCLUSION}

After Bulgaria's accession to the European Union, the wine sector in Bulgaria has undergone significant changes. Attempts to replace traditional trade channels with new ones linked to the European market have led to reduced levels of exports. The Common

market is characterized by high levels of competition, with Bulgarian products competing with the more popular ones from Italy, France, Portugal, Spain and others. The uncertainty about the realization of Bulgarian wine already produced led to a decrease in the investments in the sector and limited opportunities for optimal operation of the vineyards. To date, the unsatisfactory levels of competitiveness of Bulgarian wine have led to a deterioration of wine-growing sector in the country.

It is necessary to take steps to promote Bulgarian wine on the European market in order to reduce the risk associated with the realization of the produced quantities. The full utilization of the vineyards in connection with the optimal realization of the produced 
products is a necessary condition for the development of the Bulgarian wine growing.

\section{REFERENCES}

1. COMTRADE

2. Agricultural Report of MAF

3. Kanchev, I., Doychinova, Y., Miteva, A., Stoyanova, H. (2012). Sustainable development of

1. The wine sector in the South Central area. Sofia: IC - UNWE.

4. Toteva, D. (2014). Influence of the common the EU's agricultural policy on the development of wine growing. Sofia,UNWE Sofia.
5. Slavova, Y., Atanasova, M., Kovacheva, T., Koteva, N., Bashev, H., Mladenova, M., Pantaleeva, D. (2011). "Competitive opportunities of the agrarian sector ". EIA.

6. Balieva, G. N., M. Huliyan (2015). Production and supply of regional food products - incentives and challenges for small holdings in Bulgaria. International Journal of Science and Research, Online ISSN 2319-7064, Volume 4, Issue 2 February 2015, 576-580. (Available at: http://www.ijsr.net/archive/v4i2/v4i2_01.ph p\#sthAsh.ablyMD1V.dpbs) 